\title{
Rehabilitation and treatment of spinal cord tumors
}

\section{Vishwa S. Raj, LaTanya Lofton}

Department of Physical Medicine \& Rehabilitation, Carolinas Rehabilitation, Charlotte, NC, USA

Context: Due to advances in acute oncological treatment, patients with spinal cord tumors exhibit improved survival. However, these patients have not received the full benefits of rehabilitation services to address their neurological deficits and rehabilitation goals.

Objective: To evaluate the epidemiology and pathophysiology of spinal cord tumors, address methods of acute oncological management, review treatment for neurological sequelae, and understand the implications as they relate to rehabilitation.

Methods: An extensive literature review was performed regarding the epidemiology, pathophysiology, acute oncological management, neurological sequelae, and rehabilitation for patients with spinal cord tumors. Databases used included pubmed.gov and OVID, as well as individual journal and textbook articles.

Results: Access to treatment should be increased given improved survival and functional deficits for patients with spinal cord tumors. Individuals can benefit from inpatient rehabilitation programs, in spite of increased medical co-morbidity and neurological deficits. Specific areas of improvement include functionality, mood, quality of life, and survival. Adjustments to treatment plans must incorporate medical complications from cancer and its treatment, perceived quality of life, and prognosis.

Conclusions: Patients with spinal cord tumors who participate in rehabilitation programs show general improvement in function, mood, quality of life, and survival. Adaptations to care plans should be made to accommodate medical co-morbidities from cancer and its treatment, patient perceptions, and prognosis.

Keywords: Neurological manifestations, Recovery of function, Spinal cord neoplasms, Spinal cord injuries, Rehabilitation, Therapeutics, Quality of life

\section{Introduction}

The treatment of spinal cord tumors in the rehabilitation setting is challenging, when considering the functional deficits from spinal cord involvement, medical co-morbidity due to cancer, and individual life expectancy. ${ }^{1}$ The primary goal of rehabilitation in this context is to improve quality of life and functional independence. ${ }^{2}$ When combined with improvements in medical, radiation, and surgical oncology care, rehabilitation can serve to integrate patient and family efforts to improve function with a multidisciplinary team approach and prevent future complications from neurological compromise. $^{3}$ This is especially important given that a high percentage of patients with metastatic spinal cord compression are able to discharge to home. ${ }^{4}$ Although life expectancy has improved for patients with spinal tumors due to both earlier detection and advances

Correspondence to: Vishwa S. Raj, Department of Physical Medicine \& Rehabilitation, Carolinas Rehabilitation, 1100 Blythe Boulevard, Charlotte, NC 28203, USA. Email: vishwa.raj@carolinashealthcare.org in oncological treatment, issues surrounding patient fragility and complications from concurrent medical treatment have prevented full access to rehabilitative services. ${ }^{5}$ The purpose of this review is to understand the epidemiology, pathophysiology, acute oncological management, management of neurological sequelae, and rehabilitation implications for patients with spinal cord tumors.

\section{Epidemiology and pathophysiology}

Metastatic spinal tumors are not uncommon, with over 18000 new cases diagnosed yearly in North America and up to $70 \%$ prevalence in patients with cancer. ${ }^{6}$ With $10 \%$ of new onset spinal cord injuries (SCI) due to tumor compression, cancer represents up to $26 \%$ of non-traumatic SCI admissions to inpatient rehabilitation units. ${ }^{7}$ Tumors are defined by their point of origin, and are described in one of two ways. Primary tumors arise from the central nervous system (CNS) directly, whereas secondary or metastatic tumors spread from sites distant to the spinal cord; metastatic 
lesions accounts for $85 \%$ of all oncological SCI. ${ }^{8}$ Primary tumors generally occupy the intradural and intramedullary space, but secondary tumors are typically extradural in nature. Although rare, secondary tumors can metastasize to intradural and intramedullary locations. The most common origins of secondary disease are lung, breast, kidney, prostate, and thyroid cancers, with bone serving as the third most common site of metastases and vertebrae the most common site of metastases in the bone. ${ }^{9}$ Symptomatic lesions are most often diagnosed in the thoracic region presenting with motor incomplete paraplegia, though cadaveric studies have shown the most common site of vertebral tumor burden in the lumbar spine. ${ }^{7}$

Primary tumors of the spinal cord are less common than secondary tumors. Intradural tumors are extramedullary and mainly consist of meningiomas, neurofibromas, and Schwannomas, all of which are typically cured with surgical resection. ${ }^{10}$ Intramedullary primary spinal cord tumors are relatively rare, accounting for $4-5 \%$ of all primary CNS lesions. Fifty-six percent of these tumors are described as benign, whereas $31 \%$ are considered malignant. Ependymomas and astrocytomas represent the majority of primary spinal tumors. Due to the rarity of these tumors, limited population-based incidence data exist that outlines prevalence by spinal levels and clinical outcomes. ${ }^{11}$ These intramedullary tumors vary widely, with focal involvement of a few centimeters to diffuse entanglement along the entire length of the spinal cord. Low-grade astrocytomas and ependymomas have better rates of cure if completely resected, whereas high-grade astrocytomas have a poorer prognosis similar to that of glioblastoma multiforme (stage IV astrocytoma). ${ }^{12}$ Patients with primary tumors who completed inpatient rehabilitation programs had a median survival of 9.5 months with 1 -year survival of $47.4 \%$, and 5-year survival of $10.5 \%$, whereas patients with secondary tumors had a median survival of 2.8 months with 1-year survival of $21.4 \%$ and 5-year survival of $3.6 \%{ }^{13}$

The most common cause of dysfunction in secondary disease is extradural epidural cord compression. Two theories explain the mechanism by which tumor metastasizes. With tumor embolization, cancer cells can spread through the vascular system and deposit into the vertebral bodies. Bony lesions can be either osteolytic, which involves destruction of normal bone, or osteoblastic due to the deposition of new bone. Both types of lesions can cause vertebral body instability. The bony instability may lead to retropulsion of bony fragments into the epidural space after vertebral body collapse. In addition, the tumor itself may grow and impinge the thecal sac anteriorly, thus compressing the spinal cord and epidural venous plexus. An alternative mechanism may involve the spread of tumor cells directly via the pre-vertebral lymphatic system into the epidural space. Seeding can then progress along the subarachnoid space to the spinal cord. Lesions of the cervical and thoracic spine are most often the result of lung and breast disease, whereas lumbosacral involvement is most often due to prostate, colon, or pelvic involvement. ${ }^{14}$ These are generally described as extradural lesions as they are located outside of the meninges. Survival rates are variable based on tumor pathology; lung metastases often yield the poorest survival rate, with $50 \%$ survival rate at 1 month and at best $16 \%$ after 24 months. Breast and prostate cancer have the best survival rates with $44 \%$ for breast and $25 \%$ for prostate after 24 months. ${ }^{15}$ There is, however, a tail to survival curves and some patients may require high levels of long-term care for at least 3 years or more. ${ }^{16}$

\section{Acute oncological management}

Management of spinal tumors varies according to the stability of the spine, neurological status, and pain. ${ }^{17}$ Treatment options mainly include surgical intervention, radiation therapy, and chemotherapy. Gross surgical resection of the tumor is recommended when possible, and has been shown to improve median survival rates by at least 6 months. ${ }^{18}$ For lung cancer, postoperative performance status also yielded improved survival. ${ }^{19}$ Indications for surgery include paraplegia lasting not more than 12-24 hours in patients with prior radiation to the spine, spinal instability, or bony compression of the spinal cord; ideally, radiation therapy should be considered as an adjuvant treatment as early as possible post-operatively and with a relatively short duration. ${ }^{20}$ The primary goals for surgical management are to preserve neurological function and reduce pain, with as minimal intervention as possible to prevent further medical complications. ${ }^{21}$ Potential problems from surgical intervention include respiratory complications, instrument failure, deep venous thrombosis, pulmonary embolism, cerebrospinal fluid leak, and wound infection and/or dehiscence, especially after adjuvant radiation therapy. ${ }^{22}$ Although uncommon, myelopathy is a potential side effect of radiation therapy. It presents either acutely within $4-6$ months, or is delayed by $1-2$ years. Symptoms may include sensations of electrical shock within nerve root distributions, weakness and sensory loss below the level of radiation, and complete SCI with loss of sphincter control. Acute forms often resolve within a few months, whereas delayed versions are progressive and can be chronic. ${ }^{23-25}$ 
Certain primary spinal cancers, such as lymphoma, neuroblastoma, and germ cell tumors, are amenable to treatment with chemotherapy. Chemotherapy can also be used as an adjuvant therapy for secondary spinal disease, including breast, prostate, and myeloma metastatic to the spine. ${ }^{26}$ For those patients with hormonedependent paraplegia from prostate cancer, aggressive hormonal treatment with surgical decompression is recommended for treatment. ${ }^{27}$ As part of a chemotherapeutic regimen, corticosteroids are often used to decrease oxidation injury and ischemic edema at the CNS level. Steroids are prescribed at high doses, with prolonged tapering schedules that decrease the overall dose by one-third to one-half every 4-5 days. Significant variability exists regarding the initial amount of dexamethasone and weaning schedule, but initial doses can range from 4 to $100 \mathrm{mg}$ given every 6 hours. Noted side effects from high-dose steroid use include hyperglycemia, increased risk of infections, gastrointestinal irritation, mood disorder, fluid retention, and impaired wound healing. ${ }^{26}$ Steroid-induced myopathy should also be considered if individuals develop proximal muscle weakness within a few days of steroid initiation; this risk has to be balanced with the potential positive effects of edema and pain control in the tumor patient. ${ }^{28}$ It is often recommended to use gastrointestinal prophylaxis to limit possible ulceration with concurrent steroid use.

Acute oncological management can yield improved functionality in individuals treated for spinal cord tumors. For patients with good ambulatory status prior to surgery, surgical intervention offers the best potential to maintain ambulation status after intervention. ${ }^{29}$ Positive prognostic factors for ambulation when receiving radiation therapy include treatment with glucocorticoids and intervention less than 12 hours after the loss of ability to walk; with improved ambulation status, patients generally experienced less pain. However, when individuals had more than one spinal epidural metastasis, they were less ambulatory. ${ }^{30}$ Multivariate scale scoring may help predict ambulation status and survival when assessing similar positive prognostic factors. ${ }^{31}$

Although neurological injury from upper thoracic spinal tumors is common due to small spinal canal size at the cervicothoracic junction and tenuous blood supply to the affected area, surgical intervention yields improved Frankel grade classification by at least one level post-operatively and also pain symptoms. ${ }^{32}$ Surgical intervention when combined with radiation therapy has shown gains regarding bladder dysfunction, the ability to void without an indwelling urinary catheter, and pain. ${ }^{33}$ These combined effects are particularly important when complete surgical resection is not possible, as is the case for certain higher-grade intramedullary astrocytoma tumors. ${ }^{34}$ For prostate cancer with metastases to the spine specifically, improvements in mobility, daily life activities, and sphincter control were noted after radiation therapy. ${ }^{35}$ However, even with gross total resection, up to $20 \%$ of late-stage deterioration can be expected from tumor recurrence; symptoms may include spinal cord pain, impaired sensitivity, urinary sphincter dysfunction, sexual dysfunction, chronic motor disorders, and cord tethering. ${ }^{36}$

\section{Management of neurological sequelae}

Neurological complications from spinal cord tumors are secondary to spinal cord compression, plexopathy, or radiculopathy, and are the result of loss of neuronal pathways at or below the level of the lesion. Although these issues may be common to all patients with SCIs, some of these conditions may be further complicated due to the primary cancer or metastatic disease. ${ }^{37}$

Pain is reported to be one of the most common complications of neoplastic spinal cord compression. ${ }^{37-39}$ It is the most frequent first symptom in patients with spinal cord compression due to cancer, and may present several months prior to neurological symptoms. ${ }^{40,41}$ The pain initially fluctuates prior to becoming more constant, and is the result of vertebral lesions causing bony destruction, spinal cord compression, vertebral instability, or spinal nerve root impingement. ${ }^{37}$ The quality and nature varies according to the location of the tumor. ${ }^{2}$ For example, tumors causing impingement of a nerve root may cause radicular pain symptoms radiating in the distribution of the affected nerve root. Additionally, pain may be exacerbated by exercise, and has also been shown to have a major effect on a person's quality of life. ${ }^{42-44}$ Several options are available for treatment including bracing for vertebral body stability, modalities (including heat, cold, ultrasound, and electrical stimulation), and medications. Although potential exists for metastatic spread of disease with modalities that promote increased blood flow, the clinical effects of pain relief may outweigh potential for tumor seeding especially if the disease process is significantly metastatic and tumor has already spread by different mechanisms. The World Health Organization outlines several medication treatment options, including non-steroidal anti-inflammatories, anti-convulsants, tricyclic antidepressants, steroids, and opioids. ${ }^{45}$ Considerations should be made, however, for the sideeffect profiles of each medication, as it relates to the individual's functional status and cancer diagnosis. For neuropathic pain specifically, both gabapentin and 
pregabalin have been shown to decrease symptoms associated with spinal cord and nerve injury. ${ }^{46-49}$

Most spinal cord tumors cause upper motor neuron bowel dysfunction. ${ }^{2}$ This may result in constipation and impaction due to inadequate emptying of the bowels. ${ }^{50}$ Constipation can also be a common complication associated with opioid pain medication. This may be intensified by immobility and malnutrition, which can further exacerbate pain. A bowel program should be initiated to aid with effective bowel evacuation and prevent pain with defecation. ${ }^{3,51,52}$ Medications should include stool softeners, stimulant laxatives, and suppositories combined with digital stimulation. Caution must be taken with digital stimulation due to increased risk of mucosal fragility, and digital stimulation is not initiated in patients with neutropenia or severe thrombocytopenia. ${ }^{53}$ The goals of the program are to prevent incontinent bowel movements and to allow adequate evacuation of the bowels within 60 minutes of initiation. ${ }^{54-57}$ For a bowel program to be effective, the program should be scheduled at a consistent time 30 minutes following a meal to take advantage of the gastrocolic reflex, and performed at least every 2 days. ${ }^{50,57,58}$ Depending on the location of the tumor and cord compression, a reflexic bowel is a possible presentation of lower motor neuron bowel dysfunction. In this case, oral bulk forming agents are necessary to maintain firm stool in order to perform manual evacuation usually on a daily basis. ${ }^{57}$ Again, special consideration to avoid digital manipulation of the rectal mucosa should be given in cases of neutropenia and severe thrombocytopenia.

Bladder dysfunction is a common late complication of spinal epidural cord compression and may present with various symptoms including urgency, frequency, retention, incontinence, and frequent urinary tract infections (UTI). ${ }^{2,37}$ True neurogenic bladder may result in either lower or upper motor neuron symptoms due to suprasacral or sacral compression of the cord or roots. The goals of bladder management are to empty the bladder effectively, maintain adequate bladder pressures, prevent hydronephrosis and vesicoureteral reflux, sustain social continence, and reduce risk of kidney disease and UTI. ${ }^{58}$ Full assessment of bladder function has been shown to improve continence by determining the most adequate means of bladder emptying. Methods for bladder management in this patient population include timed voiding, intermittent catheterization, and indwelling catheters. ${ }^{37}$ Caution is again necessary with neutropenia and severe thrombocytopenia.

Decreased or absent sensation of the skin may increase the patient's risk of pressure ulcer development.
Pressure ulcers can be worsened by moisture due to prolonged sitting and decreased mobility, bowel and bladder incontinence, and malnutrition. Pressure ulcers are preventable, and maintenance of skin integrity is vital. ${ }^{2}$ Education of the patient should include appropriate techniques for pressure relief as well as information regarding the importance of nutrition. ${ }^{2,59}$ Additionally, radiation treatments can cause increased skin fragility due to cell damage throughout the various layers of skin in which radiation passes. Radiation dermatitis is characterized by erythema, edema, and desquamation in early phases of exposure to radiation therapy. Late changes may include hair loss, telangiectasias, atrophy and fibrosis of the skin, loss of pigmentation, and ulceration. Gentle washing of the skin with water or soap and water within the field of radiation can decrease the risk of acute skin reaction. ${ }^{60,61}$

Sexual dysfunction may be the result of SCI, primary cancer itself, or oncological treatment effects. Both SCI and cancer may cause changes in body image, sensation, and function that may alter the person's perception of sexual attractiveness. ${ }^{62,63}$ The rehabilitation program should include assessment of the patient's neurological injury and the impact of this injury on the patient's sexual response. ${ }^{64}$ The extent of sexual dysfunction will be dependent upon whether the patient has complete or incomplete SCI. Further radiation therapy, chemotherapy, and depression may also affect sexual function. Assessment of the bulbocavernosous reflex (BCR) and completeness of an injury may help to understand an individual's capability for arousal. ${ }^{64,65}$ Both psychogenic and reflexogenic erections are parasympathetic in nature, whereas psychogenic control may be possible through sympathetic nervous system stimulation. ${ }^{66}$ For patients with complete SCI and absence of the BCR, the ability for reflexogenic erections and lubrication is diminished. Physiological orgasm is unlikely in patients with complete injuries with absence of BCR and anal wink reflex. ${ }^{64,67}$ Treatment options for sexual dysfunction include education, counseling, oral medications, and assistive devices (such as vacuum device, intraurethral agents, and intracavernous injection therapy). ${ }^{64}$

\section{Rehabilitation implications}

In addition to SCI, it is important to understand the inherent medical co-morbidity associated with cancer diagnoses. Supportive care is essential to optimize an individual's medical status and improve the rehabilitation course. ${ }^{68}$ Cancer-related fatigue is the most prevalent symptom experienced by individuals with cancer. 
Evaluation and treatment of organic factors, such as anemia, are often easily correctable. However, other causes of fatigue must be considered, such as: depression; infection; metabolic factors from the tumor; radiation effects, including radiation-induced hypothyroidism and central effects from the radiation itself; sedation from centrally acting drugs and pain medications; and overall tumor burden. Although pain may be secondary to compressive and destructive mass effects, it may also be due to post-operative pain syndromes, radiation therapy, and chemotherapy. Patients are more susceptible to both anorexia and cachexia. Gastrointestinal tract disorders may include dysphagia after radiation, esophagitis, decreased motility from pain medications, and obstruction from tumor. Consideration should also be made for decreased caloric intake due to diminished appetite and malaise, competition between tumor and host for nutrients, and tumor-elaborated and -induced factors from paraneoplastic syndromes that could impair the desire to eat. Careful attention is needed to address disorders of mood, such as anxiety, depression, and delirium. These conditions are common in cancer patients, and may be secondary to the following: adjustment from diagnosis of a terminal condition; chemotherapy or radiation effects to the brain; intra-abdominal malignancy; hypercalcemia from bone involvement of the tumor; hypothyroidism as a side effect of radiation or chemotherapy; infections; nutritional issues, such as vitamin $\mathrm{B}_{12}$ deficiency; opioid pain medications; and organic dysfunction from direct CNS effects of the tumor. Dyspnea is also common. Factors that may affect breathing include: cachexia and wasting of the respiratory muscles, malignant ascites to the abdomen causing limited diaphragmatic excursion, metastatic disease to the lung, and poor premorbid medical status secondary to preexisting cardiopulmonary disease. $^{69}$

Paraneoplastic syndromes are secondary to autoimmune responses to a primary tumor at a distant site, which then causes neuromuscular dysfunction. Common symptoms include cerebellar degeneration from ovarian carcinoma, myasthenic syndromes and myopathy from small-cell lung carcinoma, and myasthenia gravis from thymoma. ${ }^{70}$ Infection is also common, and could be due to neutropenia from chemotherapy, concurrent steroid use, and hypogammaglobinulemia secondary to hematological disorders. ${ }^{71}$ In cancer patients proximal deep venous thrombosis (DVT) is common, and patients are more likely to have greater initial tumor burden and greater clinical deterioration in spite of anticoagulation therapy. Risk factors for
DVT include extrinsic vascular compression, obstruction of venous return due to invasion, blood flow stasis, endothelial injury, increased coagulation activity due to tumor release of pro-coagulant factors and inflammatory mediators, increased platelet aggregation, central venous catheter placement, and anti-neoplastic treatments. ${ }^{72}$ Anemia is multifactorial and may be due to chemotherapeutic interventions which facilitate anti-mitotic mechanisms to slow down tumor growth but unintentionally decrease marrow production of red blood cells. Additional factors contributing to anemia involve vitamin deficiencies (such as iron, folate, and vitamin B12), chronic bleeding, renal insufficiency due to increased protein loads produced by the tumor, bone marrow suppression from tumor invasion, and chronic illness. ${ }^{73}$

Appropriate decisions for plans of care should account for acknowledgment of the phase of a patient's illness, likely gains from treatment, and potential for morbidity and toxicity with intervention. ${ }^{74}$ With a diagnosis of spinal tumor, patients face a difficult adjustment due to denial of their disability, understanding new boundaries, concern about dependence on others, and learning to live within a new normality. ${ }^{75}$ Quality of life may be inconsistent between that perceived by health care professionals and that perceived by the patient, and may be affected by both physical and non-physical issues, including independence, freedom from pain, and family support. ${ }^{76}$ When designing a rehabilitation program, special attention is needed regarding individuals' perception of quality of life, which could be influenced by both spiritual well-being and level of education. ${ }^{77}$ It is also important to have early discussion regarding advanced directives and resuscitation orders; less than half of patients at a major cancer center with metastatic spinal cord compression had a "do not resuscitate" note. ${ }^{78}$ Even with improved survival and benefits from a rehabilitation plan of care, prognosis should still be an important factor when designing the goals of a rehabilitation program. $^{79}$

Rehabilitation does have positive effects in patients with spinal cord tumors. Patients with benign tumors tend to have the most improved neurological recoveries. ${ }^{80}$ However, individuals with malignancy have also shown overall improvements in function, mood, quality of life, and survival after inpatient rehabilitation. Over $84 \%$ of patients with neoplastic spinal cord compression were able to discharge to home. They maintained improvements in upper and lower extremity dressing, grooming, toileting, tub transfers, wheelchair use, ambulation, and stair climbing 3 months after 
discharge. ${ }^{37}$ Patients with American Spinal Asia Injury Impairment Scale $\mathrm{A}-\mathrm{C}$ classification also experienced decreased pain, utilization of opioids, and measures of depression. They were more satisfied with life, and had better ability to transfer independently and manage bowel and bladder programs at home. ${ }^{81}$ Appropriate bowel and bladder care is important to prevent major complications and discomfort from insensate skin due to neoplastic SCI. ${ }^{82}$ Use of incentive spirometry, optimal nutritional supplementation, management of mood, and education in skin care issues contributed to an improved survival of 20 weeks. ${ }^{83}$ Patients who survived greater than 1 year after discharge from inpatient rehabilitation experienced less medical complications, higher Frankel classification level (D), and decreased return admissions to the hospital. ${ }^{84}$ Additional factors that could improve survival include less aggressive tumor pathology, slow progression of neurological symptoms, treatment with both surgery and radiation therapy, SCI as the presenting sign of malignancy, partial bowel control on admission, and partial independence regarding transfers at the time of admission to rehabilitation. ${ }^{85}$ Longer-term survival for spinal cord malignancy has been noted for: total functional independence (FIM) measure score of 65 or greater on admission; Frankel classification of B, C, or, D; good wheelchair mobility; and good walking ability. ${ }^{86}$ In contrast, patients with total FIM gain less than or equal to 13 had significantly poorer survival, though it has been noted that an increased length of stay did lead to higher overall FIM changes. ${ }^{87}$

When outlining a plan of care, it is important to understand that patients with spinal cord tumors may have to be assessed differently than patients with traumatic SCI. Patients with neoplastic cord involvement are generally older, female, and not employed; upon presentation they are incomplete and paraplegic with involvement at the thoracic levels, and have a decreased inpatient rehabilitation length of stay compared to traumatic injuries. ${ }^{88}$ The primary source of cancer does not necessarily impact the functional evolution of individuals participating in rehabilitation programs, but accommodations have to be made based on concomitant cancer-related disorders, such as cachexia, fatigue, psychological factors, and adverse effects from primary treatment of the oncological process. Clinical evaluations must factor in how immobility, effects from pain medication, and malnutrition may affect gastrointestinal motility and nutrition. Unfortunately, due to the often incomplete nature of the injury, patients who use Valsalva maneuvers to trigger bowel movements may also suffer from significant back pain given spinal involvement of the tumor. In this patient population, it is not unreasonable to consider indwelling urinary catheters for patients who cannot void spontaneously or who have contraindications to receive intermittent catheterization, such as severe thrombocytopenia or leukopenia. ${ }^{89}$ Patients with neoplastic spinal involvement may lack the ability to perform intermittent catheterization due to pain. Neurogenic complications from upper motor neuron lesions, such as detrusor sphincter dyssynergia and neurogenic detrusor overactivity, may make indwelling urinary catheter use appropriate in spite of increased risks of complications such as UTI or bladder calculi. ${ }^{90}$ Of note however, for patients who complete inpatient rehabilitation with normal bladder function and survive greater than 1 month after discharge, $72 \%$ retained normal bladder function. ${ }^{91}$ In addition, constant vigilance is needed regarding metabolic factors from the cancer itself, which can cause fatigue and can adversely affect neurologic tissue, thus causing both central and peripheral neurological deficits. ${ }^{89}$ With concurrent malnutrition and effects from radiation, wound complications may pose significant problems. ${ }^{92}$ Pressure sores that exist prior to the rehabilitation admission may also contribute to longer of length of stay due to wound care needs. ${ }^{86}$

\section{Conclusions}

As survival after treatment for spinal cord tumors improves, it is important to understand how to apply rehabilitation principles and practices to this patient population. Full access to treatment is still limited due to concerns about fragility and medical complexity associated with this diagnosis. Patients with spinal cord tumors can benefit from inpatient rehabilitation programs, in spite of their increased medical co-morbidity from the disease process itself, acute oncological management, and neurological sequela. Improvements have been shown in areas of functionality, mood, quality of life, and survival when participating in inpatient rehabilitation. Variations of traditional methods for care of the SCI patient are necessary to account for medical complications from cancer and its treatment, individual's perception of quality of life, and life expectancy.

\section{References}

1 Carr J, Finlay P, Pearson D, Thompson K, White H. Neurological tumours and associated conditions. In: Rankin J, Robb K, Murtagh N, Cooper J, Lewis S, (eds.) Rehabilitation in cancer care. Oxford: Blackwell Publishing Ltd; 2008. p. 99-108.

2 Kirshblum S, O’Dell MW, Ho C, Barr K. Rehabilitation of persons with central nervous system tumors. Cancer 2001; 92(4 Suppl.):1029-38. 
3 Abrahm JL, Banffy MB, Harris MB. Spinal cord compression in patients with advanced metastatic disease: 'all I care about is walking and living my life. JAMA 2008;299(8):937-46.

4 Guo Y, Young B, Palmer JL, Mun Y, Bruera E. Prognostic factors for survival in metastatic spinal cord compression: a retrospective study in a rehabilitation setting. Am J Phys Med Rehabil 2003; 82(9):665-8.

5 Palacio A, Calmels P, Genty M, Le-Quang B, Beuret-Blanquart F. Oncology and physical medicine and rehabilitation. Ann Phys Rehabil Med 2009;52(7-8):568-78.

6 Jacobs WB, Perrin RG. Evaluation and treatment of spinal metastases: an overview. Neurosurg Focus 2001;11(6):E10.

7 McKinley WO, Seel RT, Hardman JT. Nontraumatic spinal cord injury: incidence, epidemiology, and functional outcome. Arch Phys Med Rehabil 1999;80(6):619-23.

8 McKinley W. Rehabilitation of patients with spinal cord dysfunction. In: Stubblefield MD, O’Dell MW, (eds.) Cancer rehabilitation: principles and practice. New York: Demos Medical Publishing, LLC; 2009. p. 533-50.

9 Heary RF, Bono CM. Metastatic spinal tumors. Neurosurg Focus 2001;11(6):E1.

10 Chamberlain MC, Tredway TL. Adult primary intradural spinal cord tumors: a review. Curr Neurol Neurosci Rep 2011;11(3): 320-8.

11 Hsu S, Quattrone M, Ostrom Q, Ryken TC, Sloan AE, BarnholtzSloan JS. Incidence patterns for primary malignant spinal cord gliomas: a surveillance, epidemiology, and end results study. J Neurosurg Spine 2011;14(6):742-7.

12 Bowers DC, Weprin BE. Intramedullary spinal cord tumors. Curr Treat Options Neurol 2003;5(3):207-12.

13 Tan M, New P. Survival after rehabilitation for spinal cord injury due to tumor: a 12-year retrospective study. J Neurooncol 2011; 104(1):233-8.

14 Drudge-Coates L, Rajbabu K. Diagnosis and management of malignant spinal cord compression: part 1. Int J Palliat Nurs 2008;14(3):110-6.

15 Fattal C, Fabbro M, Gelis A, Bauchet L. Metastatic paraplegia and vital prognosis: perspectives and limitations for rehabilitation care. Part 1. Arch Phys Med Rehabil 2011;92(1):125-33.

16 Cowap J, Hardy JR, A'Hern R. Outcome of malignant spinal cord compression at a cancer center: implications for palliative care services. J Pain Symptom Manage 2000;19(4):257-64.

17 Wetzel FT, Phillips FM. Orthopedic management of metastatic disease of the spine. Orthop Clin North Am 2000;31(4):611-21.

18 Sundaresan N, Sachdev VP, Holland JF, Moore F, Sung M, Paciucci PA, et al. Surgical treatment of spinal cord compression from epidural metastasis. J Clin Oncol 1995;13(9):2330-5.

19 Ogihara S, Seichi A, Hozumi T, Oka H, Ieki R, Nakamura K, et al. Prognostic factors for patients with spinal metastases from lung cancer. Spine 2006;31(14):1585-90.

20 Rades D, Karstens JH. A comparison of two different radiation schedules for metastatic spinal cord compression considering a new prognostic factor. Strahlenther Onkol 2002;178(10):556-61.

21 Rompe JD, Hopf CG, Eysel P. Outcome after palliative posterior surgery for metastatic disease of the spine-evaluation of 106 consecutive patients after decompression and stabilisation with the Cotrel-Dubousset instrumentation. Arch Orthop Trauma Surg 1999;119(7-8):394-400.

22 Kim JM, Losina E, Bono CM, Schoenfeld AJ, Collins JE, Katz $\mathrm{JN}$, et al. Clinical outcome of metastatic spinal cord compression treated with surgical excision \pm radiation versus radiation therapy alone: a systematic review of literature. Spine 2012;37(1):78-84.

23 Woodley R, Martin D. Chronic nontraumatic myelopathies. In: Lin V, (ed.) Spinal cord medicine: principles and practice. New York: Demos Medical Publishing, LLC; 2002. p. 419-27.

24 Rampling R, Symonds P. Radiation myelopathy. Curr Opin Neurol 1998;11(6):627-32.

25 Kamin S. Vascular, nutritional, and other diseases of the spinal cord. In: Kirshblum S, Campagnolo D, Delisa J, (eds.) Spinal cord medicine. Philadelphia: Lippincott Williams and Wilkins Publishing; 2002. p. 521-6.

26 Drudge-Coates L, Rajbabu K. Diagnosis and management of malignant spinal cord compression: part 2. Int J Palliat Nurs 2008;14(4):175-80.
27 Nagata M, Ueda T, Komiya A, Suzuki H, Akakura K, Ishihara M, et al. Treatment and prognosis of patients with paraplegia or quadriplegia because of metastatic spinal cord compression in prostate cancer. Prostate Cancer Prostatic Dis 2003;6(2):169-73.

28 Stubblefield MD, Bilsky MH. Barriers to rehabilitation of the neurosurgical spine cancer patient. J Surg Oncol 2007;95(5): 419-26.

29 Putz C, van Middendorp JJ, Pouw MH, Moradi B, Rupp R, Weidner $\mathrm{N}$, et al. Malignant cord compression: a critical appraisal of prognostic factors predicting functional outcome after surgical treatment. J Craniovertebr Junction Spine 2010;1(2):67-73.

30 Zaidat OO, Ruff RL. Treatment of spinal epidural metastasis improves patient survival and functional state. Neurology 2002; 58(9):1360-6.

31 Rades D, Rudat V, Veninga T, Stalpers LJ, Basic H, Karstens JH, et al. A score predicting posttreatment ambulatory status in patients irradiated for metastatic spinal cord compression. Int $\mathbf{J}$ Radiat Oncol Biol Phys 2008;72(3):905-8.

32 Le H, Balabhadra R, Park J, Kim D. Surgical treatment of tumors involving the cervicothoracic junction. Neurosurg Focus 2003; 15(5):E3.

33 Milross CG, Davies MA, Fisher R, Mameghan J, Mameghan H. The efficacy of treatment for malignant epidural spinal cord compression. Australas Radiol 1997;41(2):137-42.

34 Yang S, Yang X, Hong G. Surgical treatment of one hundred seventy-four intramedullary spinal cord tumors. Spine 2009; 34(24):2705-10.

35 Aass N, Fossa SD. Pre- and post-treatment daily life function in patients with hormone resistant prostate carcinoma treated with radiotherapy for spinal cord compression. Radiother Oncol 2005; 74(3):259-65.

36 Raco A, Esposito V, Lenzi J, Piccirilli M, Delfini R, Cantore G. Long-term follow-up of intramedullary spinal cord tumors: a series of 202 cases. Neurosurgery 2005;56(5):972-81.

37 McKinley WO, Conti-Wyneken AR, Vokac CW, Cifu DX. Rehabilitative functional outcome of patients with neoplastic spinal cord compression. Arch Phys Med Rehabil. 1996;77(9): 892-5.

38 Foley KM. The treatment of pain in the patient with cancer. CA Cancer J Clin 1986;36(4):194-215.

39 Collins JJ, Grier HE, Kinney HC, Berde CB. Control of severe pain in children with terminal malignancy. J Pediatr 1995;126(4): 653-7.

40 Bach F, Larsen BH, Rohde K, Borgesen SE, Gjerris F, BogeRasmussen $\mathrm{T}$, et al. Metastatic spinal cord compression, occurrence, symptoms, clinical presentations and prognosis in 398 patients with spinal cord compression. Acta Neurochir (Wien) 1990;107(1-2):37-43.

41 Helweg-Larsen S, Sorensen PS. Symptoms and signs in metastatic spinal cord compression: a study of progression from first symptom until diagnosis in 153 patients. Eur J Cancer 1994;30A(3):396-8.

42 Donnelly C, Eng JJ. Pain following spinal cord injury: the impact on community reintegration. Spinal Cord 2005;43(5):278-82.

43 Anke AG, Stenehjem AE, Stanghelle JK. Pain and life quality within 2 years of spinal cord injury. Paraplegia 1995;33(10):555-9.

44 Murray RF, Asghari A, Egorov DD, Rutkowski SB, Siddall PJ, Soden RJ, et al. Impact of spinal cord injury on self-perceived pre- and postmorbid cognitive, emotional and physical functioning. Spinal Cord 2007;45(6):429-36.

45 Jadad AR, Browman GP. The WHO analgesic ladder for cancer pain management. stepping up the quality of its evaluation. JAMA 1995;274(23):1870-3.

46 Dworkin RH, O'Connor AB, Backonja M, Farrar JT, Finnerup NB, Jensen TS, et al. Pharmacologic management of neuropathic pain: evidence-based recommendations. Pain 2007;132(3):237-51.

47 Levendoglu F, Ogun CO, Ozerbil O, Ogun TC, Ugurlu H. Gabapentin is a first line drug for the treatment of neuropathic pain in spinal cord injury. Spine 2004;29(7):743-51.

48 Cardenas DD, Warms CA, Turner JA, Marshall H, Brooke MM, Loeser JD. Efficacy of amitriptyline for relief of pain in spinal cord injury: results of a randomized controlled trial. Pain 2002;96(3): 365-73.

49 Siddall PJ, Cousins MJ, Otte A, Griesing T, Chambers R, Murphy TK. Pregabalin in central neuropathic pain associated with spinal 
cord injury: a placebo controlled trial. Neurology 2006;67(10): 1792-800.

50 Stiens SA, Bergman SB, Goetz LL. Neurogenic bowel dysfunction after spinal cord injury: clinical evaluation and rehabilitative management. Arch Phys Med Rehabil 1997;78(3 Suppl.):S86-S102.

51 Schiff D. Spinal cord compression. Neurol Clin 2003;21(1):67-86.

52 Miaskowski C, Cleary J, Burney R. Guideline for the management of cancer pain in adults and children, APS clinical practice guideline series, No 3. Glenview, IL: American Pain Society; 2005.

53 Henry RF, Rilart R. Tumors of the spine and spinal cord. In: Kirshblum SK, Campagnolo DI, DeLisa JA, (eds.) Spinal cord cedicine. Philadelphia: Lippincott Williams \& Wilkins; 2002. p. $480-97$.

54 Davis A, Nagelhout MJ, Hoban M, Barnard B. Bowel management: a quality assurance approach to upgrading programs. J Gerontol Nurs 1986;12(5):13-7.

55 Kirk PM, King RB, Temple R, Bourjaily J, Thomas P. Long-term follow-up of bowel management after spinal cord injury. SCI Nurs 1997;14(2):56-63.

56 Zejdlik CP. Reestablishing bowel control. In: Zejdlik CP, (ed.) Management of spinal cord injury. 2nd ed. Boston: Jones and Bartlett; 1992. p. 397-416.

57 Spinal Cord Medicine Consortium. Neurogenic bowel management in adults with spinal cord injury: a clinical practice guideline for healthcare providers. J Spinal Cord Med. 1998;21(3):248-93.

58 Consortium for Spinal Cord Medicine. Bladder management for adults with spinal cord injury: a clinical practice guideline for health-care providers. J Spinal Cord Med. 2006;29(5):527-73.

59 Consortium for Spinal Cord Medicine Clinical Practice Guidelines. Pressure ulcer prevention and treatment following spinal cord injury: a clinical practice guideline for health-care professionals. J Spinal Cord Med 2001;24(Suppl. 1):S40-101.

60 Balagula Y, Rosen ST, Lacouture ME. The emergence of supportive oncodermatology: the study of dermatologic adverse events to cancer therapies. J Am Acad Dermatol 2011;65(3):624-35.

61 Berkey FJ. Managing the adverse effects of radiation therapy. Am Fam Physician 2010;82(4):381-8.

62 Pelusi J. Sexuality and body image. research on breast cancer survivors documents altered body image and sexuality. Am J Nurs 2006;106(3 Suppl.):32-8.

63 Anderson KD, Borisoff JF, Johnson RD, Stiens SA, Elliott SL. Long-term effects of spinal cord injury on sexual function in men: implications for neuroplasticity. Spinal Cord 2007;45(5):338-48.

64 Consortium for Spinal Cord Medicine. Sexuality and reproductive health in adults with spinal cord injury: a clinical practice guideline for health-care professionals. J Spinal Cord Med 2010;33(3):281-336.

65 Sipski M, Alexander CJ, Gomez-Marin O. Effects of level and degree of spinal cord injury on male orgasm. Spinal Cord 2006; 44(12):798-804.

66 Sipski M, Alexander C, Gomez-Marin O, Spalding J. The effects of spinal cord injury on psychogenic sexual arousal in males. J Urol 2007;177(1):247-51.

67 Sipski ML, Alexander CJ, Rosen R. Sexual arousal and orgasm in women: effects of spinal cord injury. Ann Neurol 2001;49(1):35-44.

68 Klastersky J. From best supportive care to early palliative care. Curr Opin Oncol 2011;23(4):311-2.

69 Cheville AL. Palliative care. In: DeLisa JA, (ed.) Physical medicine \& rehabilitation: principles and practice. Philadelphia: Lippincott Williams \& Wilkins; 2005. p. 531-55.

70 Vargo MM, Gerber LH. Rehabilitation for patients with cancer diagnoses. In: DeLisa JA, (ed.) Physical medicine \& rehabilitation: principles and practice. Philadelphia: Lippincott Williams \& Wilkins; 2005. p. 1771-94.

71 Freifeld AG, Kaul DR. Infection in the patient with cancer. In: Abeloff MD, (ed.) Abeloff's clinical oncology. 4th ed. Philadelphia: Churchill Livingstone Elsevier; 2008. p. 717-8.

72 Deitcher SR. Diagnosis, treatment, and prevention of cancerrelated venous thrombosis. In: Abeloff MD, (ed.) Abeloff's clinical oncology. 4th ed. Philadelphia: Churchill Livingstone Elsevier; 2008. p. 694-6.

73 Glaspy J. Disorders of blood cell production in clinical oncology. In: Abeloff MD, (ed.) Abeloff's clinical oncology. 4th ed. Philadelphia: Churchill Livingstone Elsevier; 2008. p. 677.

74 Hicks F, Thom V, Alison D, Corcoran G. Spinal cord compression: the hospice perspective. J Palliat Care 1993;9(3):9-13.

75 Eva G, Paley J, Miller M, Wee B. Patients' constructions of disability in metastatic spinal cord compression. Palliat Med 2009;23(2): $132-40$.

76 Levack P, Graham J, Kidd J. Listen to the patient: quality of life of patients with recently diagnosed malignant cord compression in relation to their disability. Palliat Med 2004;18(7):594-601.

77 Tate DG, Forchheimer M. Quality of life, life satisfaction, and spirituality: comparing outcomes between rehabilitation and cancer patients. Am J Phys Med Rehabil 2002;81(6):400-10

78 Guo Y, Palmer JL, Bianty J, Konzen B, Shin K, Bruera E. Advance directives and do-not-resuscitate orders in patients with cancer in metastatic spinal cord compression: advanced care planning implications. J Palliat Med 2010;13(5):513-7.

79 Fattal C, Fabbro M, Rouays-Mabit H, Verollet C, Bauchet L. Metastatic paraplegia and functional outcomes: perspectives and limitations for rehabilitation care. Part 2. Arch Phys Med Rehabil 2011;92(1):134-45.

80 Catz A, Goldin D, Fishel B, Ronen J, Bluvshtein V, Gelernter I. Recovery of neurologic function following nontraumatic spinal cord lesions in Israel. Spine 2004;29(20):2278-82.

81 Ruff RL, Ruff SS, Wang X. Persistent benefits of rehabilitation on pain and life quality for nonambulatory patients with spinal epidural metastasis. J Rehabil Res Dev 2007;44(2):271-8.

82 Murray PK. Functional outcome and survival in spinal cord injury secondary to neoplasia. Cancer 1985;55(1):197-201.

83 Ruff RL, Adamson VW, Ruff SS, Wang X. Directed rehabilitation reduces pain and depression while increasing independence and satisfaction with life for patients with paraplegia due to epidural metastatic spinal cord compression. J Rehabil Res Dev 2007; 44(1):1-10.

84 Eriks IE, Angenot EL, Lankhorst GJ. Epidural metastatic spinal cord compression: functional outcome and survival after inpatient rehabilitation. Spinal Cord 2004;42(4):235-9.

85 Hacking HG, Vans As HH, Lankhorst GJ. Factors related to the outcome of inpatient rehabilitation in patients with neoplastic epidural spinal cord compression. Paraplegia 1993;31(6):367-74.

86 Parsch D, Mikut R, Abel R. Postacute management of patients with spinal cord injury due to metastatic tumour disease: survival and efficacy of rehabilitation. Spinal Cord 2003;41(4):205-10.

87 Tang V, Harvey D, Park Dorsay J, Jiang S, Rathbone MP. Prognostic indicators in metastatic spinal cord compression: using Functional Independence Measure and Tokuhashi scale to optimize rehabilitation planning. Spinal Cord 2007;45(10):671-7.

88 McKinley WO, Huang ME, Tewksbury MA. Neoplastic vs. traumatic spinal cord injury: an inpatient rehabilitation comparison. Am J Phys Med Rehabil 2000;79(2):138-44.

89 Raven RW. Rehabilitation of patients with paralyses caused by cancer. Clin Oncol 1975;1(3):263-8.

90 Reitz A, Haferkamp A, Wagener N, Gerner HJ, Hohenfellner M. Neurogenic bladder dysfunction in patients with neoplastic spinal cord compression: adaptation of the bladder management strategy to the underlying disease. Neuro Rehabil 2006;21(1):65-9.

91 Conway R, Graham J, Kidd J, Levack P, Scottish Cord Compression Group. What happens to people after malignant cord compression? survival, function, quality of life, emotional well-being, and place of care 1 month after diagnosis. Clin Oncol 2007;19(1):56-62.

92 Fattal C, Gault D, Leblond C, Gossens D, Schindler F, RouaysMabit $\mathrm{H}$, et al. Metastatic paraplegia: care management characteristics within a rehabilitation center. Spinal Cord 2009;47(2): $115-21$. 